\title{
Hermenéutica y tradición
}

\author{
Mariflor Aguilar
}

$\mathrm{E}$

1 artículo de Ambrosio Velasco "La relevancia del pensamiento de Gadamer en la filosofía: más allá de la modernidad y de la posmodernidad", ${ }^{1}$ sitúa a Gadamer en la encrucijada de diversos debates contemporáneos: entre modernidad y posmodernidad, pero también entre universalismo y contextualismo y entre comunitaristas y liberales, por lo menos, y destaca siete temas gadamerianos que lo ubican en ese difícil callejón intermedio. Se trata de un artículo que desde mi punto de vista reúne varios aciertos entre los que señalo que, a pesar de la brevedad del texto, expone cada uno de los temas con gran claridad, sin dejar de incluir aspectos relevantes de cada problema; introduce una serie de términos polémicos que enriquecen el pensamiento gadameriano, como son los que toma de Heidegger de "acontecer" y "finitud" que considero representa uno de los aportes de Gadamer más importantes a la hermenéutica contemporánea; asimismo articula el pensamiento hermenéutico no solamente con el pensamiento de las ciencias sociales, sino también con el de las ciencias de la naturaleza en la tradición de Kuhn, Lakatos y Laudan, acercando así ambas problemáticas y propiciando entre ellas un diálogo fructífero.

Voy a comentar un solo punto de este trabajo, el que se refiere al concepto de tradición. En la forma como Velasco desarrolla el punto del "Concepto gadameriano de tradición" deben destacarse por lo menos dos cosas: una es la inmediata puesta en relación de la tradición con el acontecer, y la otra es la articulación de la tradición con la "formación" (Bildung) y el "horizonte". En cuanto a esto último, no es habitual relacionar inmediatamente estos tres términos, y hacerlo contribuye a su esclarecimiento. Afirma Ambrosio Velasco

${ }^{1}$ Ambrosio Velasco, "La relevancia del pensamiento de Gadamer en la filosofía: más allá de la modernidad y la posmodernidad" en Revista del Colegio de Filosofía. Theoría, núm. 7. México, unAM, Facultad de Filosofía y Letras, diciembre, 1998, pp. 55-66. 
que lo peculiar del momento ontológico de la comprensión "consiste fundamentalmente en el diálogo que se establece entre la formación cultural propia de quien comprende y la formación cultural de la obra que se busca comprender", y añade después que "este proceso de desplazamientos de las formaciones culturales, horizontes y situaciones hermenéuticas constituye el movimiento de la tradición a la que pertenecemos". ${ }^{2}$ En estas líneas quedan articulados varios términos gadamerianos de primera importancia: el diálogo, la tradición, la formación, el horizonte y la comprensión, pero en particular se incorpora a la idea de "fusión de horizontes", no siempre bien explicada ni por el mismo Gadamer, toda la compleja elaboración de la noción de "formación" que designa el proceso mediante el cual los individuos y las culturas inscriben sus preocupaciones particulares en una perspectiva más amplia, siendo así que un individuo o un grupo formado o "cultivado" no puede ser aquel que se restringe a su mundo propio inmediato, sino aquel que participa del diálogo con los otros de quienes aprende. ${ }^{3}$ Siendo así, la fusión de horizontes deberá pensarse como el entramado que forman procesos dinámicos de formaciones culturales con posibilidades de expandirse y de entrar en diálogo, y en tanto que este entramado "constituye el movimiento de la tradición”, esta misma complejidad de procesos dialógicos se extiende al concepto de "tradición", concepto que a pesar de ser "probablemente uno de los más importantes en el pensamiento gadameriano", como dice Velasco, no queda del todo engarzado conceptualmente en los trabajos de Gadamer.

Me parece importante pensar la tradición, la comprensión, la fusión de horizontes en términos de "formación", porque tal como es trabajada por Gadamer, esta noción permite pensar toda la propuesta hermenéutica, incluyendo la interrelación de tradiciones, como un conjunto de tesis que enfatizan la posibilidad de aprender de los otros -ideas que no está de más enfatizar en nuestro descalificante presente.

En cuanto a la relación de la tradición con el "acontecer", me parece importante que se haga esta relación, pues considero que la tesis del acontecer está a la base de la reflexión gadameriana; en ésta todo "acontece": la imagen, el arte, la verdad, el diálogo, el lenguaje, la tradición. Pero ¿̨qué es el acontecer? Me parece que hay al menos dos lecturas: una es la del acontecer como 1) lo que acaece, lo que viene "de otro lado" como una herencia, y 2) que "se impone como un destino - es decir, sin correctivo posible" ${ }^{4}$ constituyendo las condiciones ya siempre dadas sólo sobre las cuales es posible la

${ }^{2}$ Ibid., p. 61.

${ }^{3}$ Cf. G. Warnke, Herméneutique, tradition et raison. Belgium, Le Point Philosophique, 1991.

${ }^{4}$ Cf. Cristina Lafont, La razón como lenguaje. Madrid, Visor, 1993, p. 77. 
comprensión del mundo y de los interlocutores en el diálogo. Esta lectura hace a la tesis del acontecer blanco de numerosas críticas en tanto que considerando el significado (2) puede leerse el diálogo gadameriano como algo que es al mismo tiempo resultado y condición de posibilidad y en esa medida, como algo "no producible mediante la conversación misma, sino necesariamente perteneciente a las condiciones que han de estar dadas para que el entendimiento sea posible". ${ }^{5}$ Pero hay otra lectura del "acontecer" que está sugerida en el texto de Velasco, que sí tiene el sentido (1) pero no el sentido (2), es decir, que sí se refiere al suelo común heredado por las tradiciones pero que no incluye la idea de fijeza ni de lo ya siempre dado. La articulación del "acontecer de la tradición" con la noción de "formación" permite pensar el diálogo entre culturas y tradiciones como un proceso siempre cambiante en el que lo transmitido es afectado por la "continuación del acontecer" en el sentido de que "el progreso de las cosas continúa determinándole a uno". 6

Me parece que la forma como Ambrosio Velasco pone en relación diversos conceptos del aparato gadameriano contribuye a clarificarlos y, por lo mismo, a hacer de los trabajos de Gadamer materiales más sugerentes.

${ }^{5}$ Ibid., p. 122.

${ }^{6}$ Hans-Georg Gadamer, Verdad y método. Salamanca, Sígueme, 1991, p. 451. 